\title{
Evaluation of Skin Friction Drag for Liner Applications in Aircraft
}

\author{
Carl H. Gerhold ${ }^{1}$, Martha C. Brown ${ }^{2}$, Christopher M. Jasinski ${ }^{3}$
}

\begin{abstract}
A parameter that is gaining significance in the evaluation of acoustic liner performance is the skin friction drag induced by air flow over the liner surface. Estimates vary widely regarding the amount of drag the liner induces relative to a smooth wall, from less than a $\mathbf{2 0 \%}$ increase to nearly $\mathbf{1 0 0 \%}$, and parameters such as face sheet perforate hole diameter, percent open area, and sheet thickness are expected to figure prominently in the skin friction drag. Even a small increase in liner drag can impose an economic penalty, and current research is focused on developing 'low drag' liner concepts, with the goal being to approach the skin friction drag of a smooth wall. The issue of skin friction drag takes on greater significance as airframe designers investigate the feasibility of putting sound absorbing liners on the non-lifting surfaces of the wings and fuselage, for the purpose of reducing engine noise reflected and scattered toward observers on the ground. Researchers at the NASA Langley Research Center have embarked on investigations of liner skin friction drag with the aims of: developing a systematic drag measurement capability, establishing the drag of current liners, and developing liners that produce reduced drag without compromising acoustic performance. This paper discusses the experimental procedures that have been developed to calculate the drag coefficient based on the change in momentum thickness and the companion research program being carried out to measure the drag directly using a force balance. Liner samples that are evaluated include a solid wall with known roughness and conventional liners with perforated facesheets of varying hole diameter and percent open area.
\end{abstract}

\section{Introduction}

Drag is recognized as a significant issue in aircraft design with one estimate by Malik, et al. ${ }^{1}$ that skin friction constitutes approximately $50 \%$ of the drag budget for long haul transports. Methods to control skin friction drag on wings and fuselage have been attempted including Discrete Roughness Elements to extend the natural laminar flow ${ }^{1}$, micro-texture ${ }^{2}$, and riblets ${ }^{3}$. Another source of skin friction drag in addition to the wing and fuselage surface is the acoustic liner mounted within the nacelle, and that drag source is the subject of this paper. Drag of the liner is receiving increased attention because of the increased fuel burn to overcome the drag. Liner drag can also be a significant parameter in future airframe designs that envision application of sound absorbing liners on non-lifting surfaces outside the nacelle ${ }^{4}$.

A number of researchers have investigated skin friction drag in liners in order to determine the effect of liner design parameters on the drag. Roberts ${ }^{5}$ measured the drag, calculating the drag coefficient from the change of the momentum thickness over axial distance, of various perforated

\footnotetext{
${ }^{1}$ Research Scientist, National Institute of Aerospace, Hampton, VA, Associate Fellow, AIAA

${ }^{2}$ Aerospace Engineer, Research Directorate, Aeroacoustics Branch, NASA, Hampton, VA

${ }^{3}$ Graduate Student, University of Notre Dame, South Bend, IN, Member, AIAA
} 
plates mounted over solid sheets and found that the equivalent sand grain height normalized by hole diameter is proportional to the square root of the perforate percent open area ratio (OAR). This is a convenient parameter because of the extensive amount of data compiled by Schlicting ${ }^{6}$ as well as others relating equivalent sand grain height to the resistance factor. Roberts did not report values of the proportionality constants. Roberts found that in-line and staggered hole patterns fit two different but parallel curves. Schetz and $\mathrm{Kong}^{7}$ determined that the drag coefficient of a liner consisting of perforate over honeycomb core is comprised of a surface roughness component, which is related to the equivalent sand grain height, plus a component due to the porosity. They compared a non-porous roughened wall, equivalent grain size of $0.041 \mathrm{~mm}$, to a porous wall with similar roughness. The non-porous roughened wall produced a drag coefficient at Mach 0.16 that was $21 \%$ greater than a smooth wall. The porous wall drag coefficient was $64 \%$ greater than the smooth wall at Mach 0.16 . They concluded that the pumping action of air through the porous surface adds to the drag from the roughened surface alone. Kong and Schetz reported similar results when the perforate consists of a porous sheet made of sintered metal ${ }^{8}$.

Wolter ${ }^{9}$, using a force balance, evaluated the drag of various perforate sheets over bulk absorber. The range of OAR was $20 \%$ to $40 \%$, and the drag coefficient was generally higher for the $40 \%$ open area perforate than for the $20 \%$ open area perforate. He looked at different hole patterns, either in-line or staggered but was not able to determine a clear pattern of skin friction drag based on hole pattern. Wilkinson ${ }^{10}$ looked at perforates over honeycomb core. The perforates ranged in OAR from 5-14\%, and the core depth was either 12.7 or $19.1 \mathrm{~mm}$. The flow speed in these tests was on the order of Mach 0.1 . He found that the drag coefficient falls into two ranges; one for which the liner drag coefficient normalized by the smooth wall drag coefficient is less than 1.2 and another for which the normalized drag coefficient is greater than 1.4. He postulates that liners for which the hole diameter and hole spacing (expressed in wall units) are both greater than 100 produce skin friction drag in the low range, while those liners for which the hole diameter and hole spacing (expressed in wall units) are both less than 100 produce skin friction drag in the high range. This implies that decreasing the percent open area (increasing hole spacing) and increasing the hole diameter together reduce drag coefficient. Drouin, et al. ${ }^{11}$ measured the drag of perforate mounted directly to a solid plate. The OAR ranged from $7 \%$ to $9 \%$ and the hole diameters ranged from 0.50 to $1.27 \mathrm{~mm}$. The researchers reported the smooth wall drag coefficient of $2.62 \times 10^{-3}$ and found that drag coefficient increased both with increasing percent open area and with increasing hole diameter. The researchers report that the increase in drag coefficient is directly proportional to the hole diameter. There appears to be an inconsistency in the relative effects of hole diameter and percent open area among the findings of researchers who have investigated these properties.

Gallman, et al. ${ }^{12}$ investigated the effect on the boundary layer growth of blowing through a liner. The liner consisted of honeycomb cells with an imbedded 2.3\% OAR septum, permeable backsheet, and $8 \%$ OAR perforate facesheet. Bias flow was injected from a plenum behind the liner. The range of mass flow injection ratio $(\mathrm{mfr})$ was $3 \%<\mathrm{mfr}<6 \%$, and the researchers found significant increase in the drag coefficient with bias flow. The increase was found to be independent of tunnel Mach number. Hwang ${ }^{13}$ looked at a liner configuration consisting of perforate sheet above a low permeable porous layer. Perforate plate thickness, $\mathrm{t}$, was $0.30<\mathrm{t}<$ $1.07 \mathrm{~mm}$, and hole size, $\mathrm{d}$, was $0.15<\mathrm{d}<0.25 \mathrm{~mm}$. Thus the aspect ratio $(\mathrm{t} / \mathrm{d})$ was as low as 1.7 
and as high as 6.0. The OAR was typically $22 \%$. The author found that for $\mathrm{t} / \mathrm{d}$ ratios in the 1 to 2 range, the drag coefficient was 50 to $100 \%$ higher than the smooth solid wall over the Mach number range 0.3 to 0.7 . For $\mathrm{t} / \mathrm{d}$ in the 4 to 6 range, the drag coefficient was approximately the same as the smooth wall for flow speeds up to Mach 0.7. Thus the thickness to hole diameter ratio appears to be a significant parameter in terms of skin friction drag. Hwang also found that blowing air through the liner actually reduces the drag coefficient and, in fact, when air is blown through the liner, drag coefficient lower than the smooth solid wall could be achieved. This is inconsistent with results found by other researchers.

Boldman and Brinich ${ }^{14}$ analyzed the friction coefficient of a liner in a tunnel with $10 \times 25 \mathrm{~cm}$ cross-section. The liner was one wall of the test section and measured $10 \times 122 \mathrm{~cm}$. The liner was perforate over honeycomb, where the honeycomb depth was $6.3 \mathrm{~mm}$. The perforate was $0.50 \mathrm{~mm}$ thick. It had $1.27 \mathrm{~mm}$ diameter holes on $4.27 \mathrm{~mm}$ centers (staggered) for $8 \%$ OAR. The friction coefficient was found to be Mach number dependent and was approximately 3\% larger than the smooth wall at Mach 0.17, 10\% larger at Mach 0.35, and 19\% larger at Mach 0.62.

It is suspected that the differences and inconsistencies among the results that were discovered during the course of the literature search can be attributed to differences in the wind tunnels or the experiment set-up. Thus, in order to develop a consistent data base for current liner designs and to investigate new design concepts, researchers at NASA Langley Research Center Liner Technology Facility deemed it necessary to develop liner drag evaluation capability in-house. Such capability is also useful for evaluating novel liner concepts for drag reduction. The decision was made to use existing wind tunnels, including the Curved Duct Test Rig (CDTR) without changing the primary purpose for which the CDTR was designed. The added advantage of utilizing the CDTR for drag measurement is that the effect of the liner on the sound propagation, or the effect of sound on the drag, can be determined in a controlled acoustic environment.

Although the drag can be measured directly using a force balance, it was not deemed economically feasible to modify the duct in order to incorporate this technology into the CDTR. The CDTR sample size is large, $38.1 \mathrm{~cm} \times 81.3 \mathrm{~cm}$, and is mounted in a vertical orientation. Additionally, the CDTR was designed as an acoustic facility and significant redesign would be required to accommodate a force balance. A method to estimate the drag indirectly, based on boundary layer profile measurements is sought instead. One such method is to curve fit the $\log$ wall region of measured boundary layer profile into a formulation ${ }^{15}$ defined by:

$$
u^{+}=\kappa \log _{10}\left(y^{+}\right)+B
$$

where $u^{+}$and $y^{+}$are expressed in wall units and the commonly accepted coefficients from the Spalding analysis are $\mathrm{k}=5.75$ and $\mathrm{B}=5.0$. The parameters $u^{+}$and $y^{+}$are both functions of the drag coefficient $\mathrm{C}_{\mathrm{D}}$, and curve fitting the measured data to this formulation provides an estimate of the drag coefficient. This formulation is derived for a solid wall and when the wall is porous, the value of the slope $\mathrm{k}$ becomes smaller and the plane of zero velocity shifts ${ }^{10,7}$. Manes et al. ${ }^{16}$ outlines a methodology to compensate for slope change and zero shift. Their work indicates the modifications that would need to be made to the CDTR experimental capability in order to acquire the data necessary to correct for flow through the liner. Given the current flow measurement capabilities of the CDTR, the porosity of the wall is seen to add to the uncertainty of the curve fit, and for this reason, the method of estimating drag coefficient from one boundary layer profile acquired over the liner is not chosen. The method that has been chosen to evaluate 
the drag in the CDTR is based on the axial change of momentum thickness, following the guidelines established by other researchers $5,11,14,12$. The momentum thickness is evaluated from the measured velocity profile as will be discussed in a later section.

One unique feature of the Curved Duct Test Rig is the ability to generate sound with a specified modal content at a specified frequency. Thus the interaction between drag and sound can be investigated. While Boldman and Brinich ${ }^{14}$ acquired most of their flow data at tunnel speeds between Mach 0.17 and Mach 0.62, they also ran tunnel velocity at Mach 0.05 with superimposed broadband noise. This was the maximum speed for which any change in the boundary layer profile could be detected when sound was injected. Authors note that broadband sound thickens the boundary layer slightly, which suggests a higher friction coefficient. Authors subjected the liner to a pure tone at $4800 \mathrm{~Hz}$ (the resonant frequency of the liner) but saw no difference in the momentum thickness. The experiences of these researchers indicate that the effect of superimposed sound on drag is expected to be small unless the sound level is high or the flow speed is low.

The purpose of the research reported in this paper is to develop a methodology for determination of skin friction drag coefficient and to develop a consistent database of the effect of liner design parameters, such as perforate hole diameter, percent open area, thickness, and honeycomb core depth, as well as external conditions, such as tunnel flow speed and sound on the drag. This capability will be used in future research to evaluate the effectiveness of unconventional liner designs.

As a cross-reference and to validate the results acquired in the CDTR, the drag of certain liner samples is measured in the wind tunnel at University of Notre Dame. This facility uses a force balance to measure the drag force directly, from which the drag coefficient is calculated. Another cross-reference that will be used in future analyses is provided by the Grazing Flow Impedance Tube (GFIT) ${ }^{17}$, which is located in the same laboratory as the CDTR. The capability of the GFIT, which like the CDTR was originally intended as an acoustic facility, is being expanded for drag measurement, in this case using the change in static pressure, which is directly proportional to the skin friction drag. Since multiple liner configurations can readily be evaluated in the GFIT, this facility is expected to serve to filter potential liner designs to select the most promising candidates for further evaluation in the CDTR and Notre Dame tunnels.

The remainder of this paper is divided into three sections. Section II is a description of the facility and the drag measurement methodology in the CDTR and in the wind tunnel at the University of Notre Dame. Section III contains the results, including comparison between CDTR and Notre Dame results for solid wall samples of known roughness and for one liner sample, discussion of the temperature effect on measurements in the CDTR, and a preliminary parameter study of conventional liners. Section IV contains conclusions and planned future work. 


\section{Description of Test Facilities}

\section{A. Curved Duct Test Rig}

The CDTR is an open-loop wind tunnel that uses a fan to draw unconditioned atmospheric air through the test section, as shown in Figure 1. The flow delivery system consists of an inlet bellmouth in a shed to prevent debris/water ingestion, $152.4 \times 76.2 \mathrm{~cm}$ vertical duct, a $90^{\circ}$ bend of $1.14 \mathrm{~m}$ average radius with turning vanes, a $152.4 \times 76.2 \mathrm{~cm}$ to $76.2 \times 76.2 \mathrm{~cm}$ transition (transition 1) followed by the flow conditioning section with screens and honeycomb and a transition to $15.2 \times 38.1 \mathrm{~cm}$. Downstream of this transition is the test section, which consists of a loudspeaker section, upstream microphone section, liner sample section, and downstream microphone section. Downstream of the test section is a diffuser/anechoic termination, a transition to a $99.1 \times 99.1 \mathrm{~cm}$ duct (transition 2), resonator, muffler, and fan. The fan is a centrifugal fan rated at $1415 \mathrm{~m}^{3} / \mathrm{min}$ and is driven by a $447 \mathrm{~kW}$ motor. The muffler and resonator are designed to reduce the fan-generated noise to $10 \mathrm{~dB}$ below the expected flow noise in the test section at Mach 0.50 .

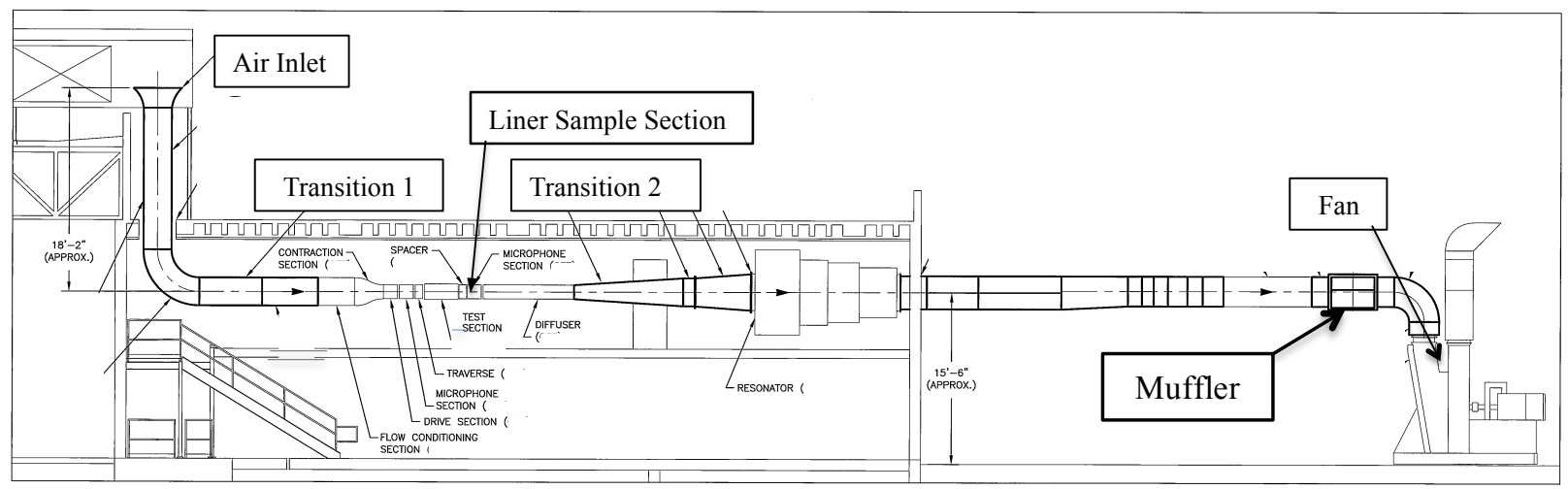

Figure 1. Drawing of the Curved Duct Test Rig layout in the Liner Technology Facility.

While the CDTR was designed as an acoustic test facility ${ }^{18}$, it is reconfigured to accommodate drag measurement using a duct section that was built for another experiment. A photograph of the Liner Drag Duct is shown in Figure 2. The test duct is $15.2 \mathrm{~cm}$ wide $\mathrm{x} 38.1 \mathrm{~cm}$ high. Flow is from right to left as shown in the photograph. The maximum flow in the test section is Mach 0.50 , and the flow profile is found to be uniform over the duct cross section with boundary layers on the order of $2.50 \mathrm{~cm}$ on each of the four walls throughout the length of the Liner Sample Section. The drag measuring capabilities combine with the acoustic capabilities to give the CDTR the unique capacity to determine the interaction between drag and sound in a full-scale liner.

The liner sample, which is typically $38.1 \mathrm{~cm}$ high x $81.3 \mathrm{~cm}$ long in the direction of flow, constitutes one wall of the duct. The liner sample is mounted on the far side of the duct shown in Figure 2. The near side has two total pressure probes mounted on linear traverses. These traverse arms are covered by the white plastic tubes, shown in the figure, to seal against air leaks in the system. The traverses are located at a vertical location of $24.1 \mathrm{~cm}$, which is $5.1 \mathrm{~cm}$ above the mid height of the $38.1 \mathrm{~cm}$ duct dimension. The total pressure in the boundary layer directly over the liner sample is measured first by the forward probe, while the downstream probe is stowed next 
to the near wall. Then the forward probe is stowed, and the downstream boundary layer is measured. Generally, data are acquired to include the entire boundary layer up to $4.58 \mathrm{~cm}$ above the liner sample. Figure 2 shows four possible traverse locations, indicated by two white circles and two white tubes, the latter of which house the traverses at locations P1 and P3. The locations at which data were acquired for this paper are P1 and P4, for which the probe tip axial locations are 9.73 and $70.68 \mathrm{~cm}$, respectively, downstream of the leading edge of the liner.

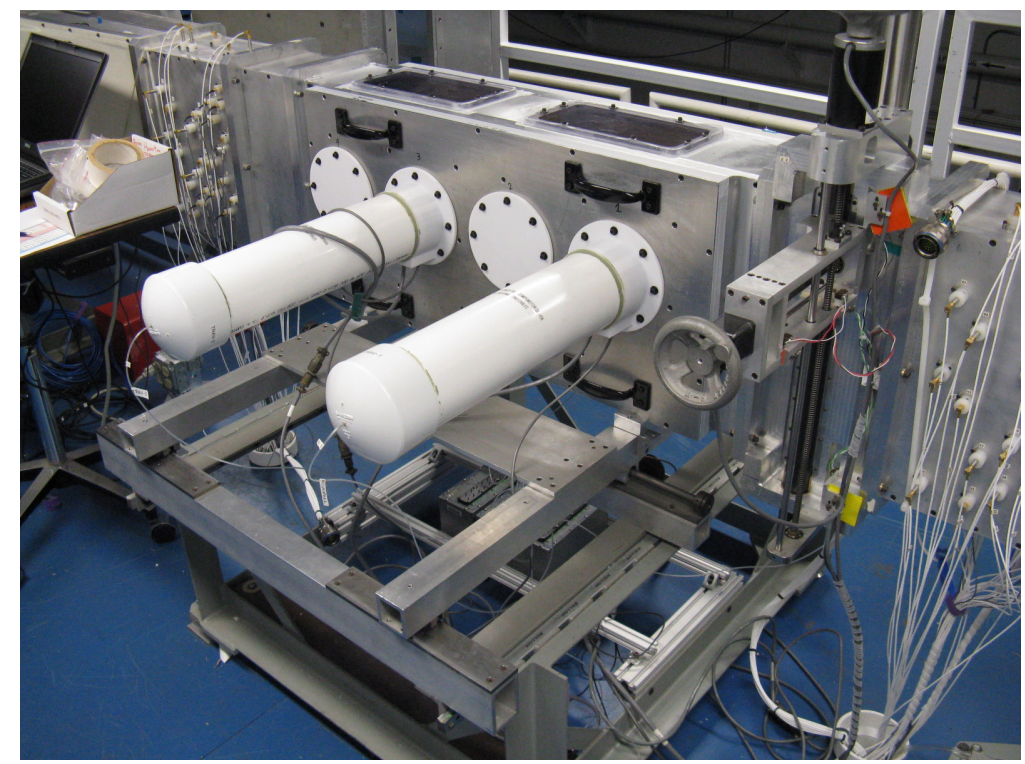

Figure 2. Photograph of Liner Drag Duct for CDTR. The white tubes contain the pressure probe traverses for boundary layer measurement, and their axial locations are interchangeable.

Figure 3 shows the interior of the Liner Drag Duct with two probes fully extended across the duct. This is for demonstration purposes only. The slot in the left wall into which one probe can be stowed while the boundary layer is being surveyed by the other probe can be seen for the forward probe. The Y-coordinate, the height above the liner surface, is measured from right to left where $Y=0.000$ is at the right-hand wall surface. The pressure probes consist of $1.02 \mathrm{~mm}$ OD thin-wall tube that is flattened at the tip to a height of $0.458 \mathrm{~mm}$. When the probe is closest to the wall, the center of the tube is at a height of $0.229 \mathrm{~mm}$. 


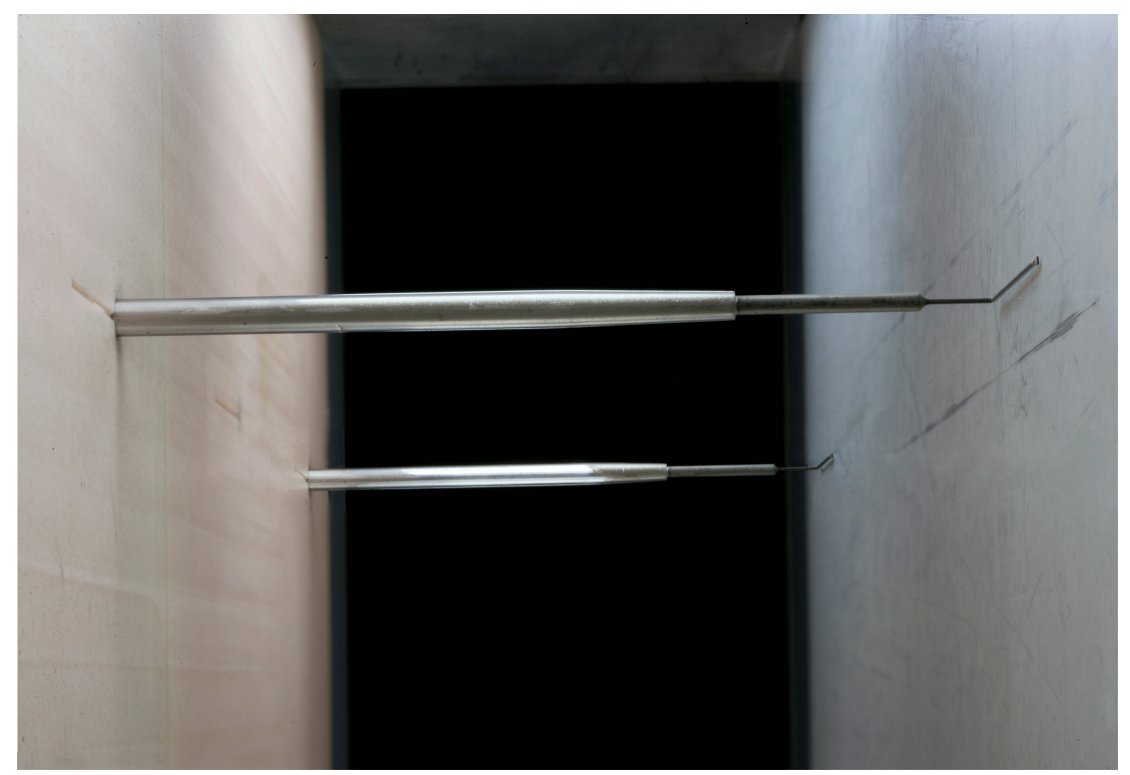

Figure 3. Total pressure probes in the Liner Drag Duct. Both probes are shown extended for demonstration purposes.

The probes are zeroed on the liner surface when the wind tunnel is at operating speed. The total pressure is measured in the boundary layer above the liner sample and is converted into the velocity profile using relationships found in NACA Report $1135^{19}$ for compressible, isentropic flow of a perfect gas. The Mach number, $M$, is derived from the ratio of static to total pressure:

$$
\frac{\boldsymbol{p}_{t}}{\boldsymbol{p}_{s}}=\left(1+\frac{\gamma-1}{2} \boldsymbol{M}^{2}\right)^{\frac{\gamma}{\gamma-1}}
$$

where:

$p_{t}=$ total pressure at the probe tip

$p_{s}=$ static pressure

$\gamma=$ ratio of specific heats

The static pressure is measured in the wall of the duct at the plane in which the total pressure is measured, and the total temperature is measured in the duct near the entrance to the Test Section. The static pressure and total temperature are recorded each time the total pressure is recorded so the conditions in the CDTR are known at every data point. The flow velocity is determined from the Mach number from:

where:

$$
U=c M
$$

$c=$ local speed of sound

The boundary layer survey consists of 112 points from $0.229<\mathrm{Y}<45.72 \mathrm{~mm}$ above the wall surface. The 112 points are non-uniformly spaced and are concentrated to obtain maximum resolution in the near wall region, $\mathrm{Y}<6.35 \mathrm{~mm}$, and at the edge of the boundary layer, $\mathrm{Y} \sim 25.4$ $\mathrm{mm}$. The pressure is averaged 200 times in 2 seconds of data acquisition time at each data point. Each 112-point survey is repeated 5 times in order to assess repeatability and the upstream and 
downstream profiles are obtained in the same session to minimize the variability caused by changes in atmospheric conditions such as ambient temperature, pressure, and humidity.

The measured flow profile is fit with a curve that incorporates an exponential term and $7^{\text {th }}$ order polynomial using a methodology that has been developed by researchers at NASA Langley Research Center:

$$
\begin{aligned}
\frac{U(y)}{U_{\infty}}= & \left(1-e^{\left(-\lambda_{0} y\right)}\right)+\lambda_{1}\left(1+\left(\left(\frac{y}{y_{\max }}\right)-1\right)\right)+\lambda_{2}\left(1-\left(\left(\frac{y}{y_{\max }}\right)-1\right)^{2}\right)+ \\
& +\lambda_{3}\left(1+\left(\left(\frac{y}{y_{\max }}\right)-1\right)^{3}\right)+\bullet \bullet+\lambda_{7}\left(1+\left(\left(\frac{y}{y_{\max }}\right)-1\right)^{7}\right)
\end{aligned}
$$

where:

$U_{\infty}=$ flow speed in the center of the duct

The curve fit routine adjusts the values of coefficients $\lambda_{0}-\lambda_{7}$ to minimize the error between the measured and calculated curves. The fit that results from using equation 2 is found to produce the lowest error from among the curve fit routines that were analyzed in this study. Note that the function forces the flow speed to 0 at $y=0.0$, which is not the case for the porous wall. It is assumed that the effect of the flow through the wall on the shape of the boundary layer is small. The parameter $y_{\max }$ is the height of the profile above the surface. In the CDTR, $y_{\max }$ is $45.72 \mathrm{~mm}$, which is well beyond the edge of the boundary layer, $\delta$, and into the uniform flow region in the middle of the duct.

The momentum thickness is evaluated from the integral of the flow speed profile, $U(y)$ over the extent of the boundary layer, $\delta$ :

$$
\Theta=\int_{0}^{\delta} \frac{U(y)}{U_{\infty}}\left(1-\frac{U(y)}{U_{\infty}}\right) d y
$$

Equation 3 is for incompressible flow and thus is a possible source of error. Research is ongoing to determine the significance of this assumption and correct for it. Two axial locations are surveyed so that the change in momentum thickness can be determined from which the skin friction drag coefficient is calculated:

$$
C_{f}=2 \frac{\Delta \Theta}{\Delta L}
$$

where:

$$
\begin{aligned}
\Delta \Theta & =\Theta_{P 4}-\Theta_{P 1} \\
\Delta L & =60.96 \mathrm{~cm}
\end{aligned}
$$

Equation 4 is valid for a negligible pressure gradient wind tunnel ${ }^{5}$. While the pressure does increase axially in the CDTR, the difference is found to be small enough that published correction factors do not reduce the uncertainty of the calculated drag coefficient. 


\section{B. University of Notre Dame Wind Tunnel}

Direct measurement of drag is accomplished in the Mach 0.6 wind tunnel at the Hessert Laboratory for Aeronautic Research at the University of Notre Dame, a photograph of which is shown in Figure 4. The Notre Dame Wind Tunnel is a low-disturbance closed return wind tunnel with free-stream air temperature control. The test section dimensions are $99.1 \mathrm{x} 99.1 \mathrm{~cm}$ crosssection by $3.0 \mathrm{~m}$ long. The Mach number range in the test section is $0.05<\mathrm{M}<0.6$, and the air temperature range in the test section is $32^{\circ} \mathrm{C}<\mathrm{T}<60^{\circ} \mathrm{C}$. The test section is modular, with three removable and fully interchangeable sections with windows on all four sides. A removable aluminum panel that can be placed at any one of the window locations in the test section has been fabricated. The panel is designed to hold the 22.9 by $22.9 \mathrm{~cm}$ test liner samples that are of the same design as those tested in the CDTR. The window panel has been machined to a high tolerance so that the gap between the test article and the aluminum panel is no more than 0.50 $\mathrm{mm}$. In this setup, the liner sample is mounted on a pair of linear air bearings. The connection to the test sample is adjustable so that the flow-side surface of the sample can be made to be flush with the inside surface of the plate to within $\pm 0.25 \mathrm{~mm}$. The panel holding the test liner sample can be located in any one of three interchangeable section locations. This allows the panel to be located at a position with different Reynolds numbers (per boundary layer height), for the same free-stream Mach number. Flow is from right to left in the photograph, and for this test the sample is mounted near the entrance to the test section.

The air bearings below the test sample are aligned in the mean flow direction. They provide a frictionless motion that is resisted by translational load cells. The load cells measure the aerodynamic force (drag) exerted on the test sample. The load cells are removable so that they can be interchanged based on the level of forces. This provides the greatest accuracy, which is based on the percentage of the full-scale reading. The four load cells that are used for the experiments have full-scale values of $0.49,0.98,2.00$ and $4.98 \mathrm{~N}$, respectively. The drag force on the $22.9 \times 22.9 \mathrm{~cm}$ test liner sample is expected to fall within this range for Mach numbers from 0.1 to 0.6. By utilizing different load cells for each Mach number, accuracy of the drag force measurement from $0.25-0.35 \%$ can be obtained. The drag coefficient is calculated from the measured drag force:

$$
C_{f}=\frac{2 F}{\rho U_{\infty}^{2} A}
$$

where:

$F=$ measured drag force

$A=$ sample area

The drag is measured at 0.1 Mach increments from Mach 0.1 to Mach 0.6. Each measurement is repeated 10 times, 5 times in the morning and 5 times in the afternoon to evaluate repeatability. 


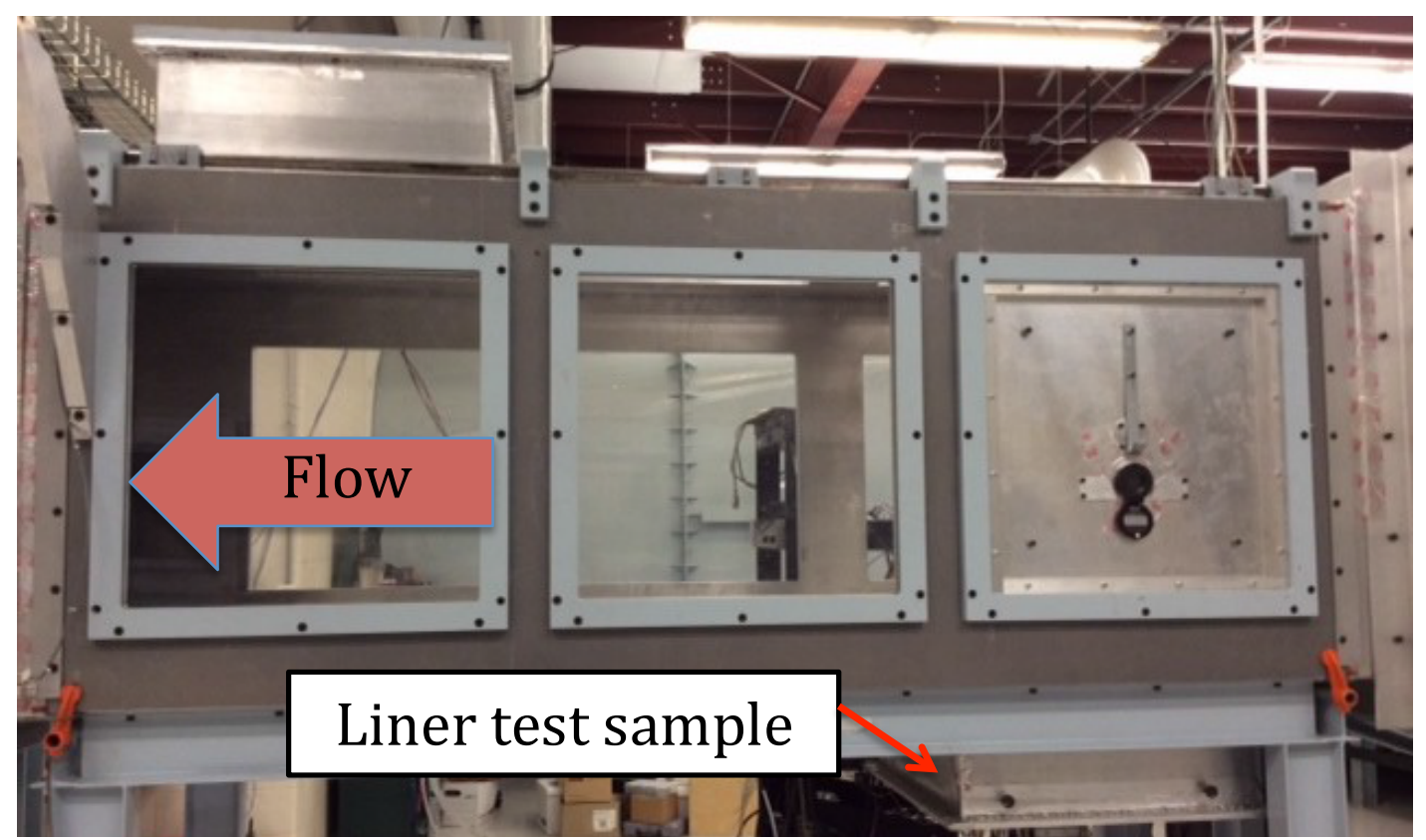

Figure 4. Photograph of the Notre Dame Wind Tunnel. Flow is from right to left. Liner sample is on the bottom wall at the right in the photograph.

The Mach number in the test section is monitored using two Pitot-static probes, one at the entrance to the test section, and one located directly over the center of the test sample, as well as a temperature sensor located at the entrance to the test section. These data are used in the wind tunnel control system to maintain a constant condition. The temperature, pressures, and drag force are stored digitally at each data acquisition point.

\section{Baseline Smooth Wall Sample}

A baseline liner has been fabricated to provide a known "smooth" wall condition. The sample for the Drag Test Duct of the NASA Langley Curved Duct Test Rig is $38.1 \mathrm{~cm}$ high $x 81.3 \mathrm{~cm}$ long. A 22.9 x $22.9 \mathrm{~cm}$ sample is fabricated for the Notre Dame Wind Tunnel facility at the same time and from the same parent material. The smooth wall samples are solid aluminum face sheet over honeycomb core with an aluminum sheet backing. The honeycomb core is $19.05 \mathrm{~mm}$ deep. The face sheet is $1.02 \mathrm{~mm}$ thick and is made from type 6062 aluminum. It is designated LA1H in the results below.

The surface parameters of the samples were measured by personnel from the Mission Assurance Branch at NASA Langley using a profile meter. The average roughness for the CDTR sample is $0.195 \mathrm{~m}-\mathrm{m}$, and $0.127 \mathrm{~m}-\mathrm{m}$ for the Notre Dame sample, both of which are considered acceptably 'smooth'. The waviness is less than $2.54 \mathrm{~m}$-m over a scan profile of $17.5 \mathrm{~mm}$ for the samples.

Roughness elements were applied to the smooth wall for the purpose of providing a "known" drag coefficient. Two heights of roughness element were chosen, $0.127 \mathrm{~mm}$ and $0.229 \mathrm{~mm}$. The higher roughness height is expected to produce a drag on the same order as the maximum liner drag and the lower roughness height is approximately midway between the smooth wall and the maximum. 


\section{Results}

\section{A. Expected Drag Coefficient}

The smooth and roughened walls were evaluated in the CDTR at flow speeds of Mach 0.3 and 0.5, and in the Notre Dame Wind Tunnel at flow speeds up to Mach 0.6. The expected drag coefficient is calculated from White ${ }^{20}$ (chapter 6):

$$
\frac{1}{\sqrt{C_{f}}}=-3.6 \log _{10}\left(\frac{6.9}{\operatorname{Re}_{D}}+\left(\frac{k / D}{3.7}\right)^{1.11}\right)
$$

where:

$k=$ roughness height

$\operatorname{Re}_{D}=\frac{U_{\infty}}{v} D$

$v=$ kinematic viscosity

$D=$ hydraulic diameter $=4 \frac{A_{c}}{P_{c}}$

$A_{c}=$ cross-sectional area of duct

$P_{c}=$ wetted perimeter of duct

This equation is for pipe flow in which all surfaces have identical roughness. This is not the case in either of the facilities in this test, but the tests are designed to provide direct comparison between a smooth wall and a roughened wall, so the drag coefficients calculated using Equation 6 should be approximately correct. Note that Equation 6 depends on the equivalent height of the roughness elements but does not explicitly depend on the density or spacing of the elements.

Table I summarizes the expected values of drag coefficient for the two roughness element types with tunnel speed using Equation 6 . The $0.127 \mathrm{~mm}$ roughness is expected to increase the drag coefficient over the smooth wall by $77 \%$ and the $0.229 \mathrm{~mm}$ roughness is expected to double the drag coefficient over the smooth wall. The drag coefficient at Mach 0.3 is approximately the same as it is at Mach 0.5, so no significant variation of drag coefficient with tunnel speed is expected except for the smooth wall.

Table I. Expected drag coefficients calculated for the CDTR

\begin{tabular}{|l|l|l|l|}
\hline \multirow{2}{*}{ Wall surface } & Roughness $(\mathrm{mm})$ & \multicolumn{2}{|l|}{ Drag Coefficient } \\
\cline { 3 - 4 } & & Mach 0.3 & Mach 0.5 \\
\hline Smooth wall & $178 \times 10^{-6}$ & $2.41 \times 10^{-3}$ & $2.22 \times 10^{-3}$ \\
\hline Medium roughness & 0.127 & $3.95 \times 10^{-3}$ & $3.93 \times 10^{-3}$ \\
\hline High roughness & 0.229 & $4.52 \times 10^{-3}$ & $4.50 \times 10^{-3}$ \\
\hline
\end{tabular}

While the drag coefficient calculation in Equation 6 does not explicitly include the density or spacing of the roughness elements, two configurations of roughness are evaluated experimentally. 
The roughness elements are manufactured by CAD-CUT and consist of dots that are die cut into $6.35 \mathrm{~mm}$ wide tape. The tape is applied to the surface and then peeled off, leaving behind a row of dots spaced $2.54 \mathrm{~mm}$ apart. In the high density configuration, the dots are installed $6.35 \mathrm{~mm}$ apart in the direction of flow for a density of $6.2 \mathrm{dots} / \mathrm{cm}^{2}$. Figure 5 shows a photograph of the roughness dots in the high density configuration applied to the smooth wall for testing in the CDTR. The high density samples for the CDTR and Notre Dame tests are designated LA5H and LA9H, respectively for the $0.127 \mathrm{~mm}(0.005 \mathrm{inch})$ and $0.229 \mathrm{~mm}(0.009 \mathrm{inch})$ roughness.

A second, low density configuration is obtained by removing every other row of dots, such that the dots are separated by $12.7 \mathrm{~mm}$ in the direction of flow. The density in this configuration is $3.1 \mathrm{dots} / \mathrm{cm}^{2}$. The configurations of roughness elements were suggested in work by Volino et al. 21. The low density samples for the CDTR and Notre Dame tests are designated LA5L and LA9L, respectively for the $0.127 \mathrm{~mm}(0.005 \mathrm{inch})$ and $0.229 \mathrm{~mm}(0.009 \mathrm{inch})$ roughness.

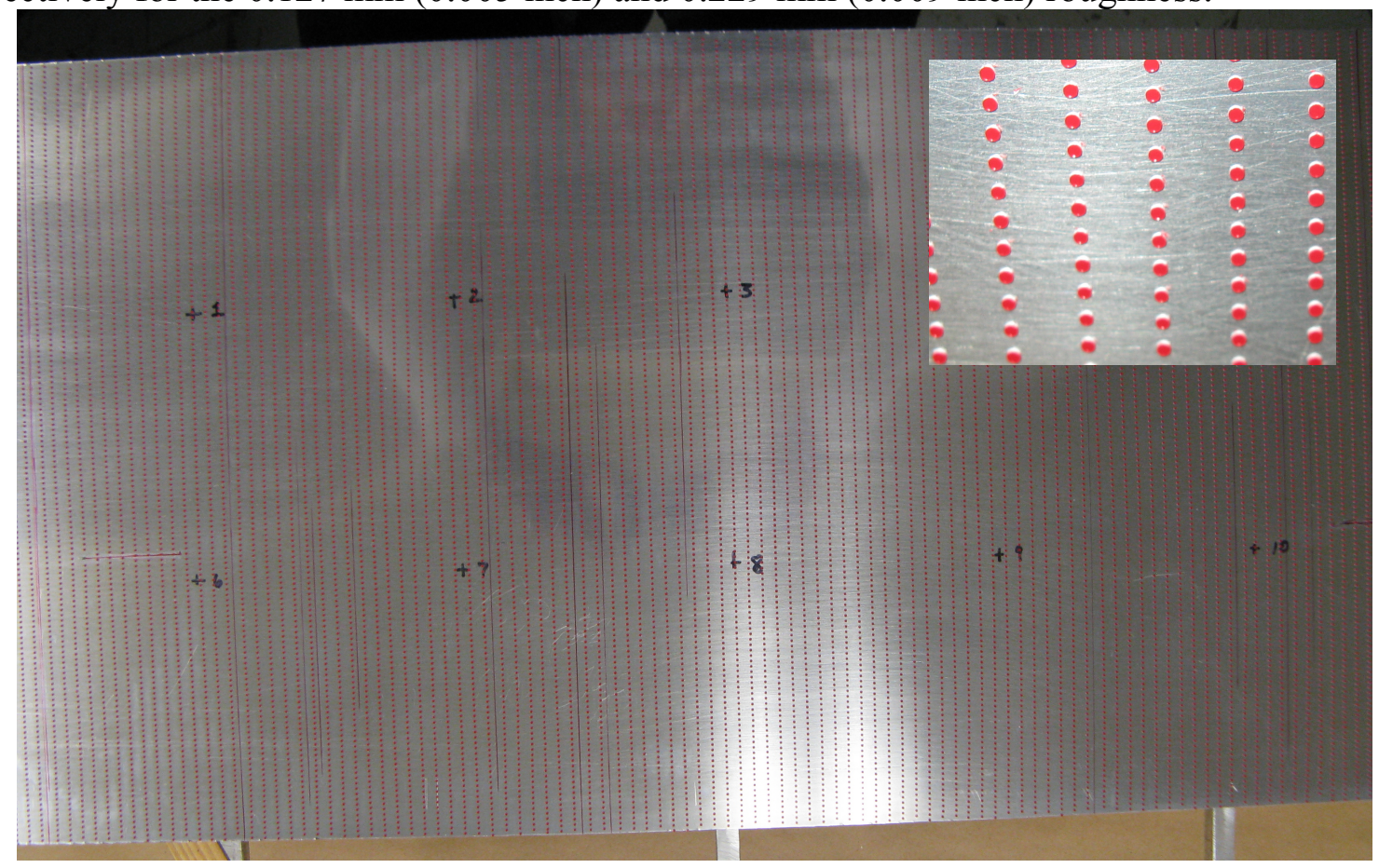

Figure 5. Photograph of CAD-CUT roughness dots, $0.229 \mathrm{~mm}$ high affixed to the Drag wall, high density configuration of $6.2 \mathrm{dots} / \mathrm{cm}^{2}$. Inset shows close-up of roughness dots.

In addition to the solid wall samples with various roughness, a standard single degree of freedom locally-reacting liner sample is also evaluated. The liner, designated L02R, consists of perforate facesheet over a $19.1 \mathrm{~mm}$ deep honeycomb core with solid back sheet. The perforate is $1.0 \mathrm{~mm}$ thick, and it has $1.0 \mathrm{~mm}$ diameter holes in a staggered pattern at $8.7 \%$ open area ratio. Liner L02R has been used extensively in the CDTR for acoustic evaluation ${ }^{22}$.

\section{B. Notre Dame Wind Tunnel Results}

Typical results of the tests in the Notre Dame Wind Tunnel on the smooth wall and smooth wall with $0.229 \mathrm{~mm}$ roughness dots are shown in Figure 6. LA1H is the smooth liner sample, LA9L is the low density of $3.1 \mathrm{dots} / \mathrm{cm}^{2}$, and LA9H is the higher density of $6.2 \mathrm{dots} / \mathrm{cm}^{2}$. The drag 
coefficient for the smooth wall case is very near the value of $2.22 \times 10^{-3}$ expected at Mach 0.5. The drag coefficient for the higher dot density is higher than the smooth wall at all flow speeds and is two times the smooth wall drag coefficient at Mach 0.5. The drag coefficient for the lower density configuration, with $3.1 \mathrm{dots} / \mathrm{cm}^{2}$ falls generally between the smooth wall and the high density configurations. The drag coefficient for each configuration is not obviously dependent on Mach number.

Since there does not appear to be a clear trend in drag coefficient with flow speed, the researchers report the average drag coefficient from measurements at the 6 Mach numbers. In addition, the values from the 10 repeats are incorporated. Thus, the standard deviation reported for the drag coefficient includes both repeatability and Mach number variation.

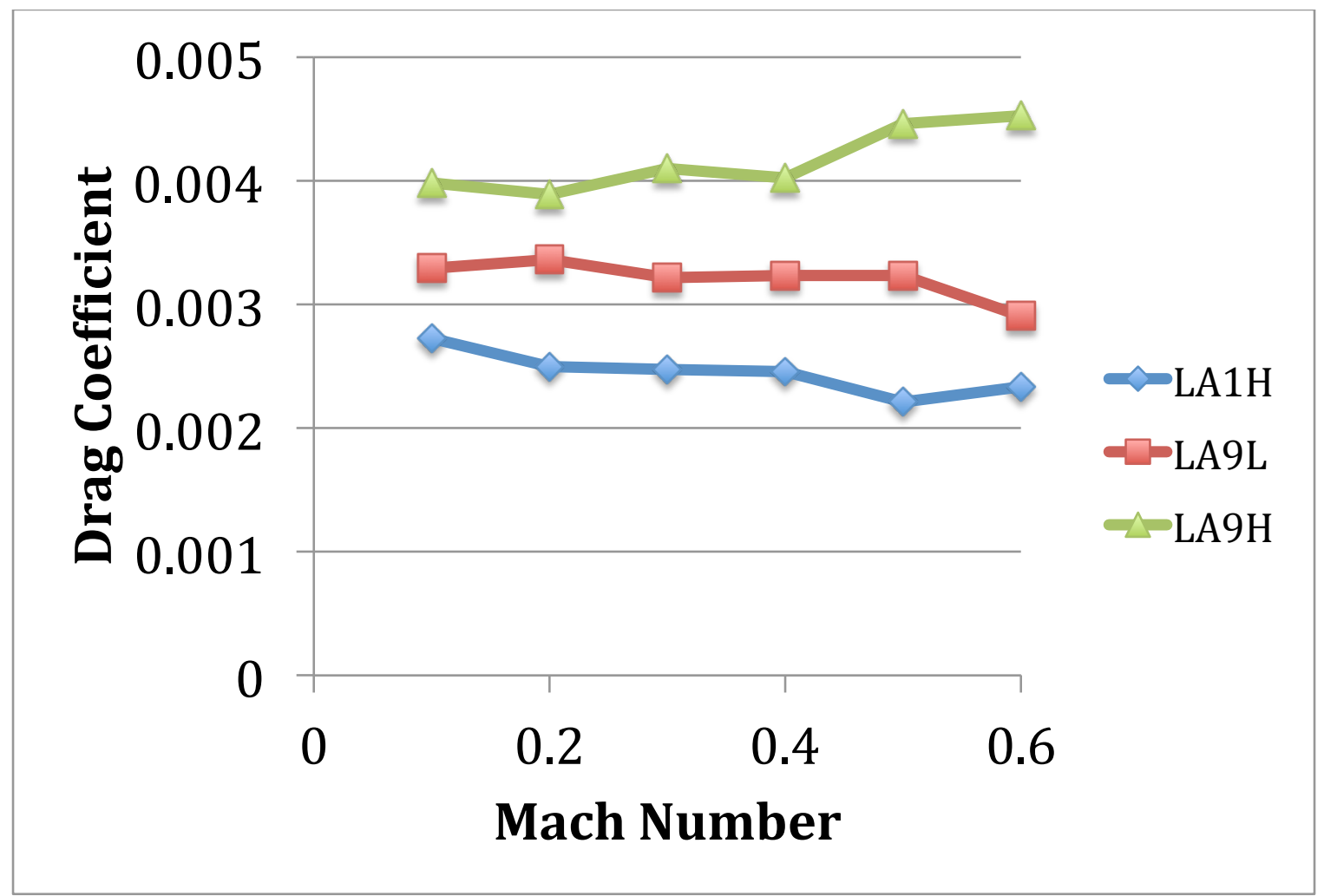

Figure 6. Typical results of drag measurement of liner samples in Notre Dame Wind Tunnel, comparing smooth wall to wall with $0.229 \mathrm{~mm}$ roughness dots applied at two densities. Data demonstrate no clear Mach number dependency of the drag coefficient.

\section{Langley CDTR Results and Comparison to Direct Measurement}

Table II shows a summary of the drag coefficient calculated using the momentum thickness data acquired at P1/P4 for two flow speeds, Mach 0.3 and Mach 0.5 compared to the average drag coefficient obtained from measurements in the Notre Dame Wind Tunnel. The standard deviations are also included, where the standard deviation includes repeatability in the Langley data and the combination of repeatability and Mach number variation in the Notre Dame data. The results are also shown in Figure 7. 
Note that the CDTR drag coefficient in the high density surface roughness configuration with the 0.229 roughness dots (LA9H) is flagged as estimated because concurrent measurements at P1 and $\mathrm{P} 4$ are not available in this case. Please see Appendix A for the calculation of the drag coefficient in this case.

Figure 7 shows that the drag coefficient increases with roughness height and, for the same height, with density of the roughness elements. The magnitude of drag coefficient increase is comparable between the NASA results and the Notre Dame direct force measurements. The NASA drag coefficients generally fall within the error bands of the direct measurements. The error for the Notre Dame measurements is greater than the error for the CDTR evaluations because the Notre Dame results include both the repeatability and Mach number variability where the CDTR results, which are obtained at two flow rates, explicitly incorporate only repeatability. Nevertheless, the uncertainty of the Notre Dame results is, with the exception of the $0.127 \mathrm{~mm}$ dots at high density, LA5H, less than $8 \%$.

Table II. Summary of drag coefficient calculated from momentum change using data acquired in the CDTR, compared with data from direct measurement in Notre Dame Wind Tunnel for samples with known roughness.

\begin{tabular}{|c|c|c|c|c|}
\hline \multirow[t]{3}{*}{ Label } & \multirow[t]{3}{*}{ Description } & \multirow[t]{2}{*}{ ND } & \multicolumn{2}{|l|}{ NASA } \\
\hline & & & Mach 0.3 & Mach 0.5 \\
\hline & & $\begin{array}{l}\text { Average } \\
\text { (std dev) }\end{array}$ & $\begin{array}{l}\text { Average } \\
\text { (std dev) }\end{array}$ & $\begin{array}{l}\text { Average } \\
\text { (std dev) }\end{array}$ \\
\hline LA1H & smooth & $\begin{array}{l}2.46 \times 10^{-3} \\
\left(1.71 \times 10^{-4}\right)\end{array}$ & $\begin{array}{l}2.38 \times 10^{-3} \\
\left(5.15 \times 10^{-5}\right)\end{array}$ & $\begin{array}{l}2.41 \times 10^{-3} \\
\left(6.54 \times 10^{-5}\right)\end{array}$ \\
\hline LA5L & 0.127 dots low density & $\begin{array}{l}2.87 \times 10^{-3} \\
\left(2.29 \times 10^{-4}\right)\end{array}$ & $\begin{array}{l}2.56 \times 10^{-3} \\
\left(7.99 \times 10^{-5}\right)\end{array}$ & $\begin{array}{l}2.69 \times 10^{-3} \\
\left(4.58 \times 10^{-5}\right)\end{array}$ \\
\hline LA5H & 0.127 dots hi density & $\begin{array}{l}3.51 \times 10^{-3} \\
\left(4.50 \times 10^{-4}\right)\end{array}$ & $\begin{array}{l}3.21 \times 10^{-3} \\
\left(1.40 \times 10^{-4}\right)\end{array}$ & $\begin{array}{l}3.33 \times 10^{-3} \\
\left(3.83 \times 10^{-5}\right)\end{array}$ \\
\hline LA9L & 0.229 dots low density & $\begin{array}{l}3.21 \times 10^{-3} \\
\left(1.51 \times 10^{-4}\right)\end{array}$ & $\begin{array}{l}3.33 \times 10^{-3} \\
\left(8.56 \times 10^{-5}\right)\end{array}$ & $\begin{array}{l}3.41 \times 10^{-3} \\
\left(8.32 \times 10^{-5}\right)\end{array}$ \\
\hline LA9H & 0.229 dots-hi density & $\begin{array}{l}4.16 \times 10^{-3} \\
\left(2.66 \times 10^{-4}\right)\end{array}$ & $\begin{array}{l}4.35 \times 10^{-3^{*}} \\
\text { (NA) }\end{array}$ & $\begin{array}{l}4.12 \times 10^{-3 *} \\
\text { (NA) }\end{array}$ \\
\hline L02R & $\begin{array}{l}\text { Liner, 8.7\% OA, } 1.0 \mathrm{~mm} \\
\text { dia }\end{array}$ & $\begin{array}{l}2.78 \times 10^{-3} \\
\left(1.66 \times 10^{-4}\right)\end{array}$ & $\begin{array}{l}2.98 \times 10^{-3} \\
\left(9.26 \times 10^{-5}\right)\end{array}$ & $\begin{array}{l}2.91 \times 10^{-3} \\
\left(6.85 \times 10^{-5}\right)\end{array}$ \\
\hline
\end{tabular}

* estimated 


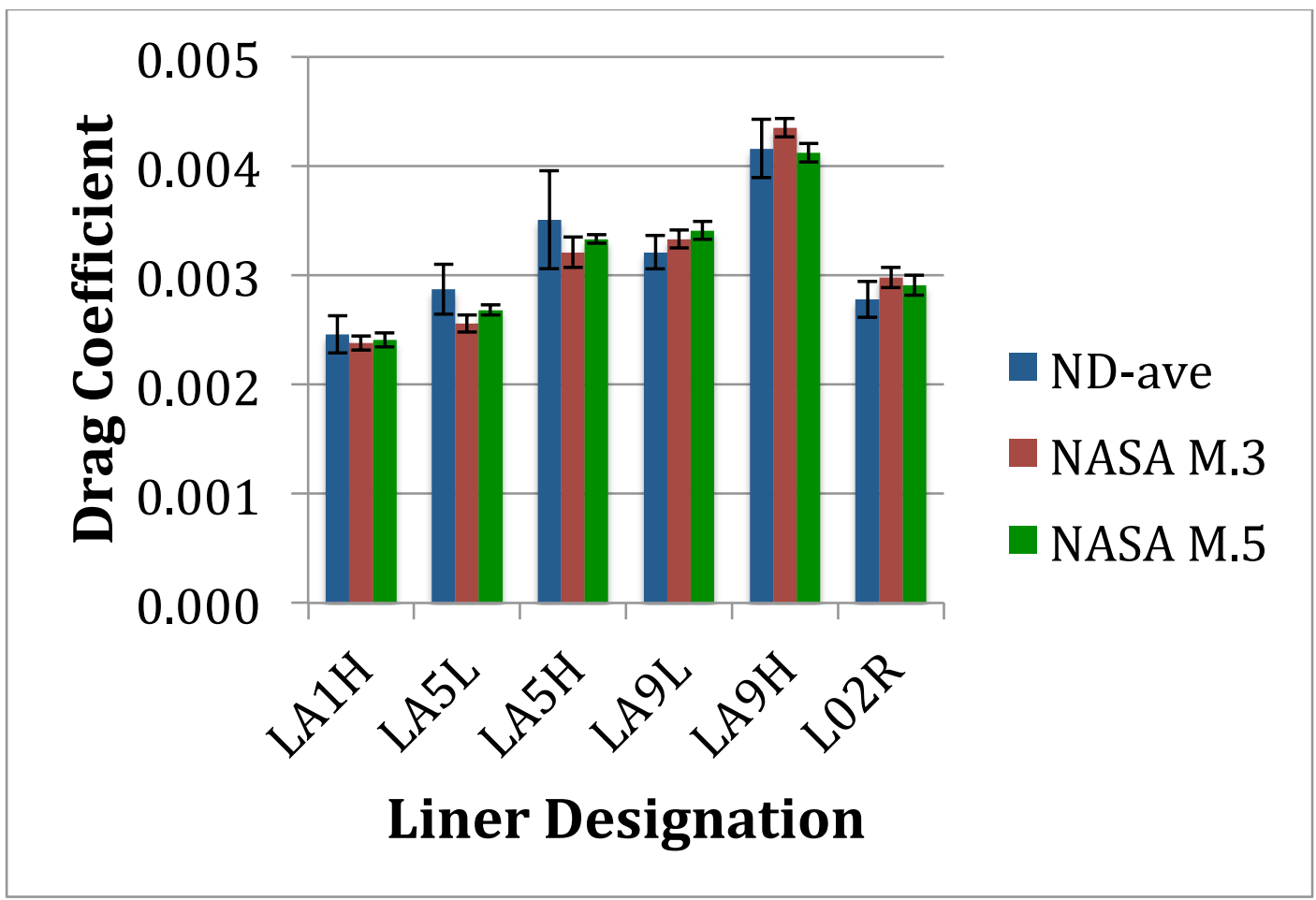

Figure 7. Comparison of drag coefficients for solid wall samples of known roughness and one acoustic liner.

The drag coefficient of the liner, L02R, is roughly equivalent to the drag coefficient of the 0.127 $\mathrm{mm}$ dots between low and high density. The liner produces a drag that is $25 \%$ greater than the smooth wall drag at Mach 0.3 and $21 \%$ greater at Mach 0.5 . The favorable comparison between the momentum change in the CDTR and the force balance measurement in the Notre Dame Wind Tunnel indicates that the drag coefficient is reliably estimated from CDTR measurements.

\section{Variation of CDTR drag determination with temperature}

Some of the hard wall liner samples without and with roughness dots were evaluated in the CDTR on multiple occasions. Since the environmental conditions in the duct cannot be closely controlled, the temperature as measured in the flow stream varied by as much as 20 degrees $(\mathrm{F})$ for these tests.

Drag measurements were made in the CDTR at different times and under varying temperatures for the smooth wall, LA1H; the wall with $0.229 \mathrm{~mm}$ roughness dots at low density $\left(3.1 \mathrm{dots} / \mathrm{cm}^{2}\right)$, LA9L, and wall with $0.127 \mathrm{~mm}$ roughness dots applied at high density $\left(6.2 \mathrm{dots} / \mathrm{cm}^{2}\right), \mathrm{LA} 5 \mathrm{H}$. The results are incorporated among those reported in the previous section, and they are also plotted separately in Figure 8. The indication from the plot is that the drag coefficient is independent of the temperature for the temperature range shown. 


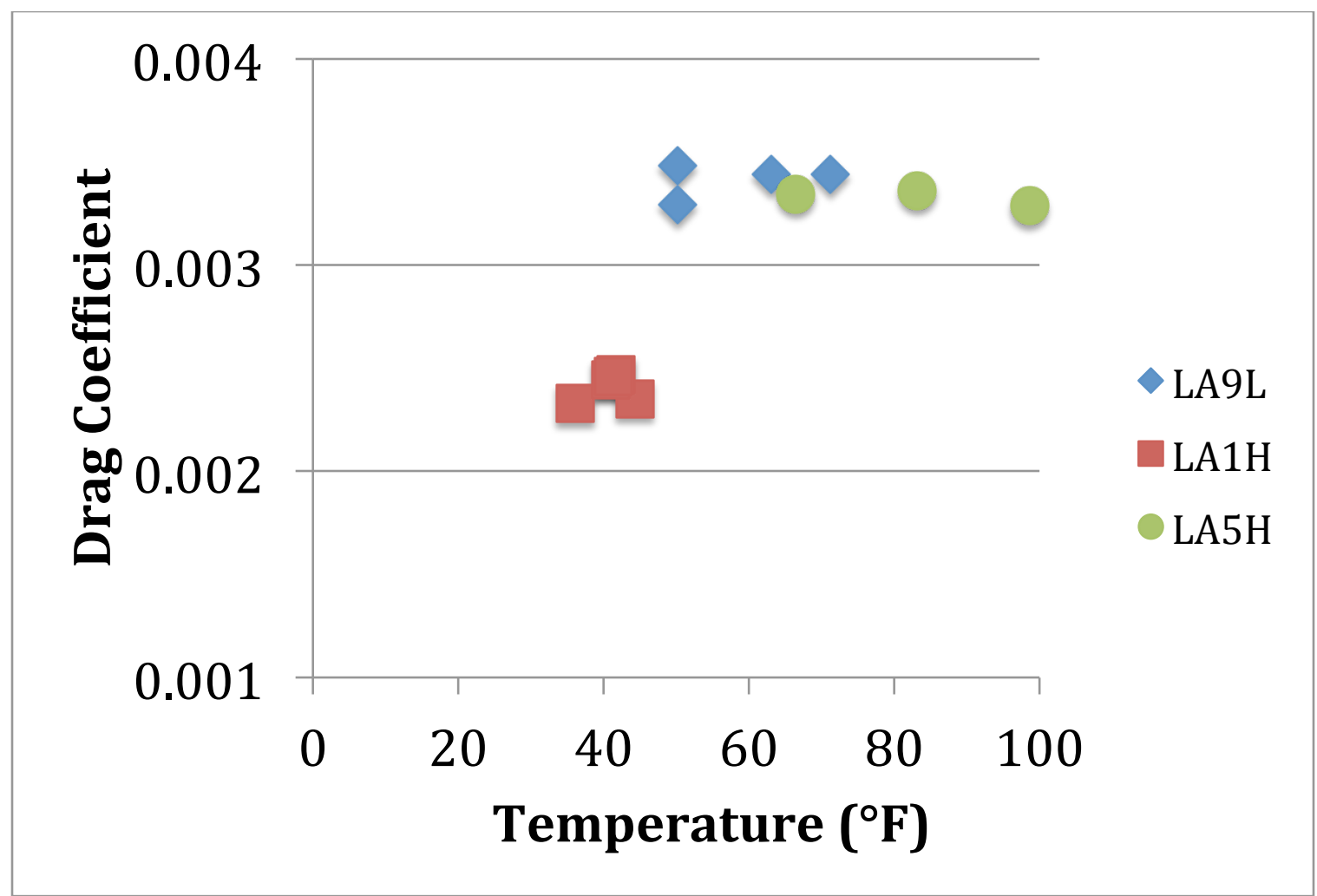

Figure 8. Temperature effect on calculated drag coefficient from momentum balance measurements in CDTR.

\section{E. Evaluation of Liner Parameters In CDTR}

The drag of several existing liner samples was evaluated in the CDTR in order to provide a preliminary look at the effect of liner parameters on drag. The liner samples are described in Table III. The table includes the hard wall sample, LA1H, and the liner L02R, which have been discussed previously. The facesheet thickness, $t$, is constant for all liner samples and two hole diameters, $\mathrm{d}, 1.0 \mathrm{~mm}$ and $2.4 \mathrm{~mm}$ are evaluated. The effect of face sheet porosities is sampled comparing a medium value of $8.7 \%$ and relatively large values of $12 \%$ and $12.8 \%$, respectively. Note that one liner, L3F is constructed with a solid sheet between the perforate face sheet and the honeycomb core. This liner was designed in an attempt to separate the roughness of the perforate from the pumping action of air trapped in the honeycomb core.

Table III. Description of liner samples for which skin friction drag is evaluated in the CDTR at Mach 0.3 and Mach 0.5

\begin{tabular}{|l|l|l|l|l|}
\hline Designation & $\mathrm{d}(\mathrm{mm})$ & OAR $(\%)$ & $\mathrm{t}(\mathrm{mm})$ & Core depth $(\mathrm{mm})$ \\
\hline LA1H & 0.0 & 0.0 & 1.0 & 19.1 \\
\hline L02R & 1.0 & 8.7 & 1.0 & 19.1 \\
\hline L3F & 1.0 & 12.0 & 1.0 & 0.0 \\
\hline L4F & 1.0 & 12.0 & 1.0 & 19.1 \\
\hline UF01 & 2.4 & 12.8 & 1.0 & 19.1 \\
\hline
\end{tabular}


The drag coefficients for these liners are shown for Mach 0.3 in Figure 9 and for Mach 0.5 in Figure 10. The results indicate that the liners generally produce greater drag than the solid sheet anywhere from $25 \%$ to $50 \%$ for the liner parameters investigated. At flow speed Mach 0.3 , Figure 9, the drag increases with increasing hole size for the same porosity, L4F to UF01, although the increase is small; and the drag increases with increasing porosity at the same hole size, L02R to L4F. Other researchers, including Howerton and Jones ${ }^{17}$ also found that the drag increases with hole size. The drag induced by the perforate facesheet alone, L3F, is less than the drag with the perforate over a core, L4F. This result is consistent with the results that Schetz and Kong ${ }^{7}$ obtained.

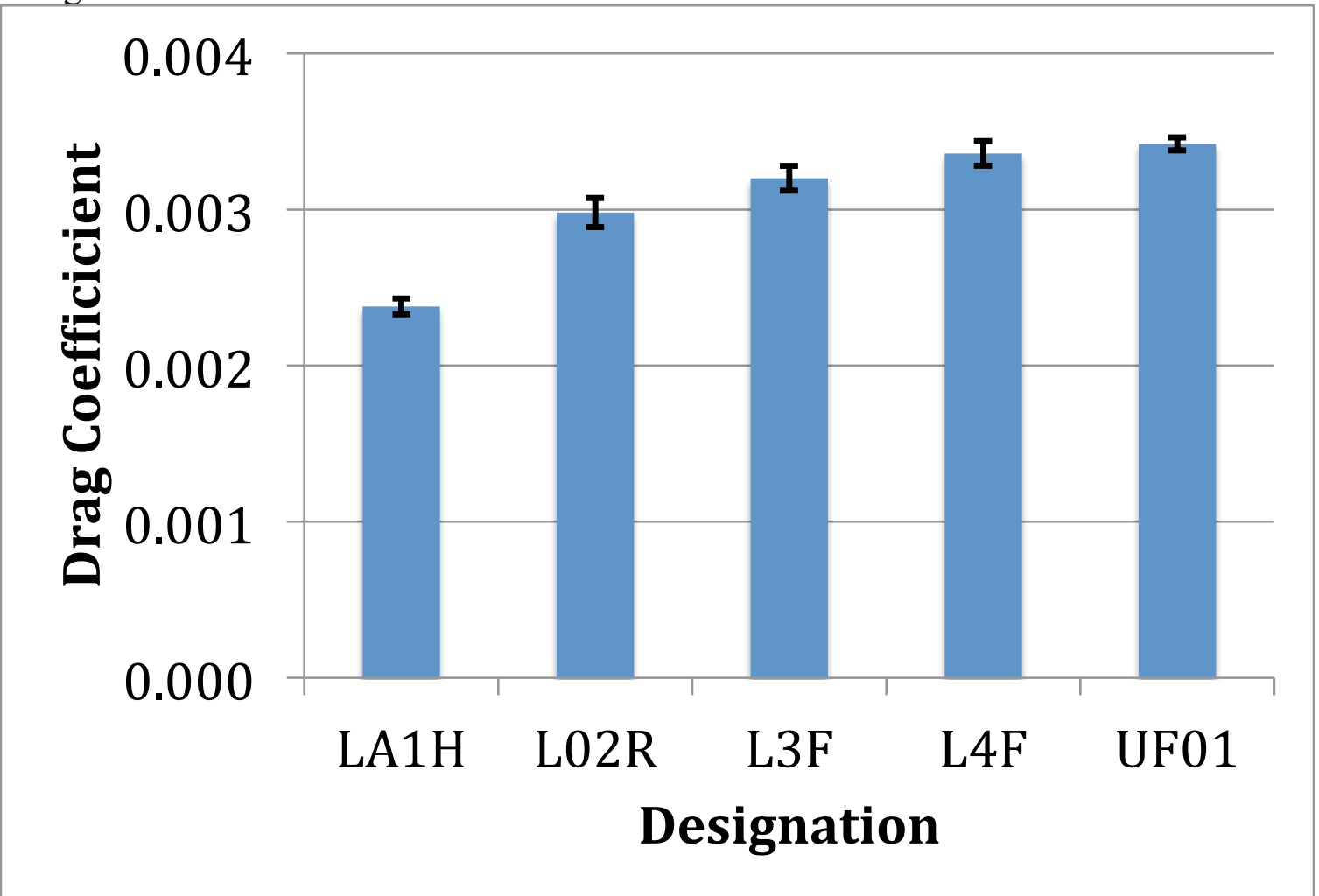

Figure 9. Calculated drag coefficient for selected liner samples in CDTR at Mach 0.3

The results at Mach 0.5 show that the drag increases with porosity at the same hole size, L02R to L4F, as was demonstrated at Mach 0.3. The results do not show as consistent an increase with hole size at the same porosity, L4F to UF01, as was expected. Also, the drag for the perforate over solid sheet, $\mathrm{L} 3 \mathrm{~F}$, is considerably higher than the drag for the perforate over honeycomb core. This result is unexpected and warrants further investigation. 




Figure 10. Calculated drag coefficient for selected liner samples in CDTR at Mach 0.5

\section{Conclusions and Future Work}

The primary purpose of this work has been to establish that the Curved Duct Test Rig, which is primarily an acoustic wind tunnel, can be adapted for use as a skin friction drag measurement facility. An integral part of this endeavor is establishing equivalence between the drag based on measurement of the momentum change in the CDTR and the drag measured directly in the Notre Dame Wind Tunnel.

Solid wall samples with known roughness, in terms both of height and of density, have been fabricated and tested in both wind tunnels. The skin friction drag increases with increasing roughness height as was expected. The values of the drag coefficients are comparable to the values expected from previous work reported in the literature. The drag also increases with increasing roughness density for the same roughness height. Not only are the trends the same for the solid wall results, the values of drag coefficient are comparable between the two experiments. There appears to be no clear trend for the drag coefficient as a function of flow speed, nor was any trend noted for variations in temperature, at least over the range of flow speeds and temperature achieved in the tests.

The drag coefficient for a sample single-degree-of-freedom perforate over honeycomb liner was found to be comparable between the two wind tunnels, as well. The liner drag was found to be roughly equivalent to the solid wall with roughness of $0.127 \mathrm{~mm}$. Several other liner types were evaluated in the CDTR. It was found that the drag coefficient increases with hole size at Mach 0.3 , which is consistent with results of other researchers. However, at Mach 0.5, the effect of 
hole size is less clear. The drag increases with increasing perforate percent open area, which result has been noted by other researchers. The drag coefficient due to the roughness of the perforate alone is less than the drag coefficient when the perforate is backed by an air-filled chamber when evaluated at Mach 0.3, although that is not the case at Mach 0.5.

A series of liner samples is currently being fabricated for evaluation in both facilities in order to establish a database of conventional liners. The liners will feature the same honeycomb core but will cover a range of perforate hole diameters from 1.0 to $2.4 \mathrm{~mm}$ and a range of percent open area from $2 \%$ to $14 \%$. Since the samples will be evaluated in both wind tunnels it is expected that more definitive conclusions about the effect of hole size and percent open area, particularly with flow speed, can be drawn from the comparative experimental results.

It was pointed out in the Introduction that liner samples with non-conventional face sheet configurations are being evaluated in the Grazing Flow Impedance Tube (GFIT). Designs can be more economically evaluated in the GFIT, and those designs that produce lowest drag without compromising acoustic performance will be replicated at the CDTR and Notre Dame scales and evaluated in the two facilities for verification.

\section{Acknowledgments}

The authors are grateful for contributions made to the successful completion of this project by the laboratory technician staff and in particular Christal Kellam of NASA LaRC for experiment set-up and operation. The authors further acknowledge Brian Howerton for his support in development of the instrumentation and data acquisition systems. The authors are grateful to Lewis Owens and Luther Jenkins of the Flow Physics and Control Branch at NASA LaRC for their consultation on boundary layer measurement techniques, law of the wall analysis, and roughness element selection and application. NASA's Advanced Air Transport Technology Project of the Advanced Air Vehicles Program and Environmentally Responsible Aviation Project of the Integrated Aviation Systems Program funded this work.

\section{References}

1. Malik, M., Liao, W., Li, F., and Choudhari, M., "DRE-Enhanced Swept-Wing Natural Laminar Flow at High Reynolds Numbers," AIAA-2013-0412, 2013.

2. Saravi, S.S. and Kai, C., "A Review of Drag Reduction by Riblets and Micro-textures in the Turbulent Boundary Layers," European Scientific Journal, vol. 9, no. 33, pp. 62-81, 2013.

3. Walsh, M.J., Sellers, W.L., and McGinley, C.B., "Riblet Drag in Flight Conditions," Journal of Aircraft, vol. 26, no. 6, pp. 570-575, 1989.

4. Czech, M.J. and Thomas, R.J., "Experimental Studies of Open Rotor Installation Effects," AIAA-2011-4047, 2011.

5. Roberts, D.W., "Equivalent Sand-Grain Roughness of Perforated Plate Acoustic Linings," AIAA-P-77-104, 1977.

6. Schlicting, H., Boundary-Layer Theory, 1979, McGraw-Hill, Inc.

7. Schetz, J.A. and Kong, F., "Turbulent Boundary Layer Over Solid and Porous Surfaces with Small Roughness," AIAA paper 81-0418, 1981.

8. Kong, F. and Schetz, J.A., "Turbulent Boundary Layer Over Porous Surfaces with Different Surface Geometries," AIAA paper 82-0030, 1982. 
9. Wolter, J.D., "Drag Measurements of Porous Plate Acoustic Liners," AIAA 2005-0803, 2005.

10. Wilkinson, S.P., "Influence of Wall Permeability on Turbulent Boundary-Layer Properties," AIAA paper 83-0294, 1983.

11. Drouin, M.K., Gallman, J.M., and Olsen, R.F., "Sound Level Effect On Perforated Panel Boundary Layer Growth," AIAA 2006-2411, 2006.

12. Gallman, J.M., Kunze, R.K., and Breer, M.D., "Measurement Of The Boundary Layer Growth Due To Transpiration Flow Through Nacelle Acoustic Liners," AIAA 2002-3063, 2002.

13. Hwang, D.P., “A Proof Of Concept Experiment For Reducing Skin Friction By Using MicroBlowing Technique," AIAA paper 97-0546, 1997.

14. Boldman, D.R. and Brinich, P.F., "Skin Friction on a Flat Perforated Acoustic Liner," AIAA Journal, vol. 14, no. 11, pp. 1656-1659, Nov. 1976.

15. Kendall, A. and Koochesfahani, M., "A Method for Estimating Wall Friction in Turbulent Boundary Layers," AIAA 2006-3834, 2006.

16. Manes, C., Poggi, D., and Ridolfi, L., "Turbulent Boundary Layers Over Permeable Walls: Scaling and Near-Wall Structure," Journal of Fluid Mechanics, vol. 687, pp. 141-170, 2011.

17. Howerton, B.M. and Jones, M.G., "Acoustic Liner Drag: A Parameter Study of Conventional Configurations," AIAA paper 2015-2230, 2015.

18. Gerhold, C.H., Brown, M.C., Jones, M.G., and Howerton, B.M., "Configuration Effects on Liner Performance," AIAA Paper 2012-2245, 2012.

19. Ames Research Staff, "Equations, Tables, and Charts for Compressible Flow," NACA Report 1135, 1953.

20. White, F.M., Viscous Fluid Flow, McGraw-Hill, 1991.

21. Volino, R.J., Schultz, M.P., and Flack, K.A., "Turbulence Structure In Boundary Layers Over Periodic Two- And Three-Dimensional Roughness,” J. Fluid. Mech., vol. 676, pp. 172$190,2011$.

22. Gerhold, C.H., Jones, M.G., and Brown, M.C., "Segmented Liner to Control Mode Scattering," AIAA Paper 2013-2078, 2013. 


\section{Appendix A. Calculation of drag coefficient for high density, $0.229 \mathrm{~mm}$ roughness element in the CDTR}

Data were not acquired at P1 for the case of the high density roughness configuration at Mach 0.3 or 0.5 , and thus it is not possible to calculate the drag coefficient in the high density roughness case based directly on measured data. The drag coefficient is estimated in the following manner. The average momentum thickness at the two locations for the three liner wall configurations (minus the reading at $\mathrm{P} 1$ for the high density configuration) are plotted in Figure A1. It is noted that the momentum thickness is nearly constant at station P1 for both the smooth wall and the low density roughness cases. It is therefore assumed that the momentum thickness equals the average of the two values shown, $2.48 \mathrm{~mm}(0.0978$ inches $)$. The drag coefficient is then estimated using the estimated momentum thickness at P1 and the average momentum thickness measured at P4 to obtain $4.12 \times 10^{-3}$. The drag coefficient for the high density roughness configuration at Mach 0.3 is similarly obtained.

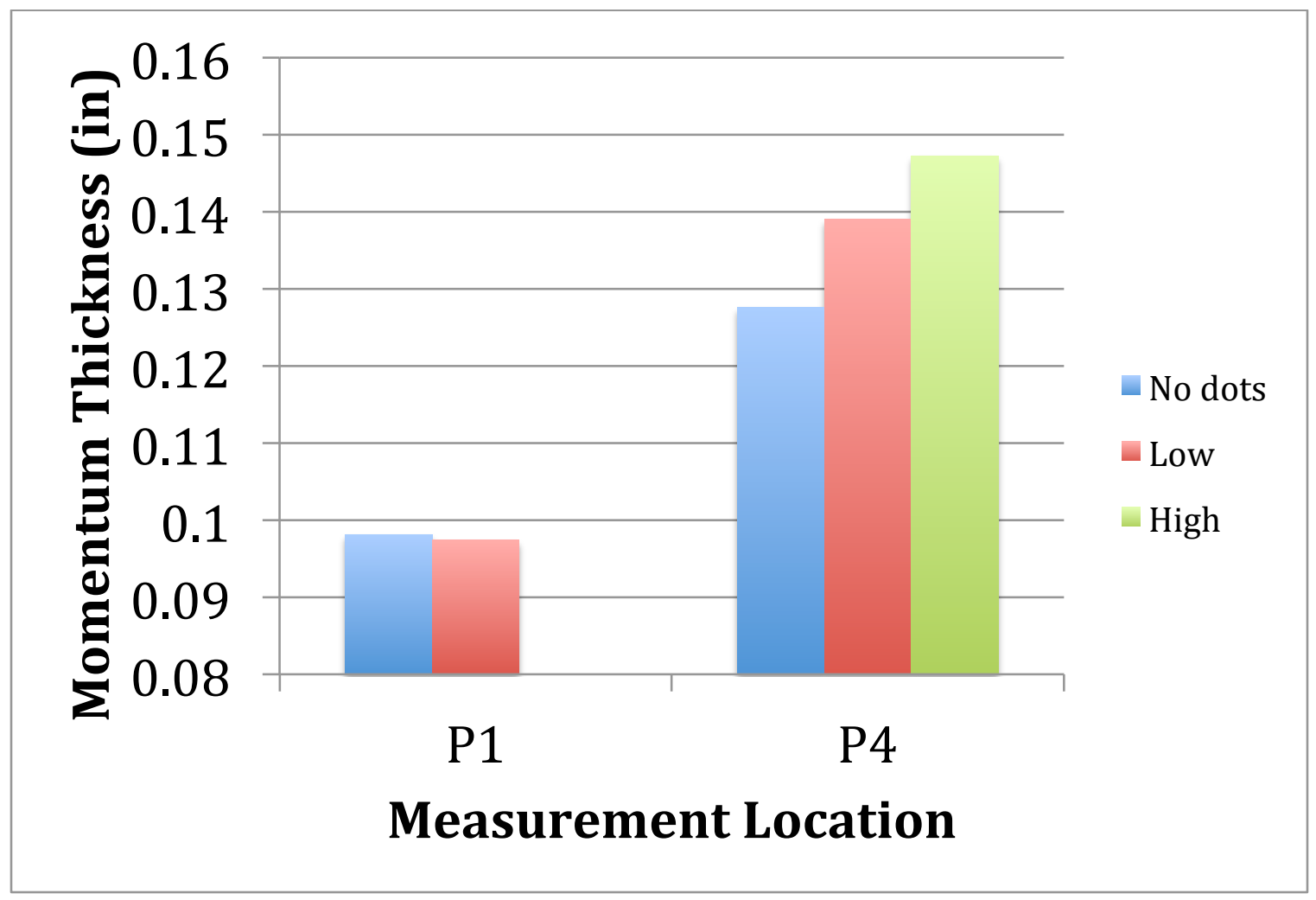

Figure A1. Momentum thickness for wall configurations in CDTR, Mach 0.5 